\title{
Vapor Treatment of Electrospray Droplets: Evidence for the Folding of Initially Denatured Proteins on the Sub-Millisecond Time-Scale
}

\author{
Anastasia Kharlamova, J. Corinne DeMuth, Scott A. McLuckey \\ Department of Chemistry, Purdue University, 560 Oval Drive, West Lafayette, IN 47907-2084, USA
}

\begin{abstract}
The exposure of electrospray droplets generated from either highly acidic or highly basic solutions to basic or acidic vapors, respectively, admitted into the counter-current drying gas, has been shown to lead to significant changes in the observed charge state distributions of proteins. In both cases, distributions of charge states changed from relatively high charge states, indicative of largely denatured proteins, to lower charge state distributions that are more consistent with native protein conformations. Ubiquitin, cytochrome $c$, myoglobin, and carbonic anhydrase were used as model systems. In some cases, bimodal distributions were observed that are not noted under any solution $\mathrm{pH}$ conditions. The extent to which changes in charge state distributions occur depends upon the initial solution $\mathrm{pH}$ and the $\mathrm{pK}_{\mathrm{a}}$ or $\mathrm{pK}_{\mathrm{b}}$ of the acidic or basic reagent, respectively. The evolution of charged droplets in the sampling region of the mass spectrometer inlet aperture, where the vapor exposure takes place, occurs within roughly $1 \mathrm{~ms}$. The observed changes in the spectra, therefore, are a function of the magnitude of the $\mathrm{pH}$ change as well as the rates at which the proteins can respond to this change. The exposure of electrospray droplets in this fashion may provide means for accessing transient folding states for further characterization by mass spectrometry.
\end{abstract}

Key words: Protein conformations, Charge state distributions, Nano-electrospray ionization

\section{Introduction}

$\mathrm{T}$ he transition of biomolecules from an unfolded conformation to a more highly ordered state is a widely studied phenomenon in structural biology. Knowledge about folding transitions can aid in the understanding of biological activity, as biological activity is often regulated by the higher order structure [1]. However, the lifetimes of many partially folded species are usually on the order of hundreds of microseconds to fractions of a second, thus making it difficult to study these intermediates using X-ray or NMR

Electronic supplementary material The online version of this article (doi:10.1007/s13361-011-0258-x) contains supplementary material, which is available to authorized users.

Correspondence to: Scott A. McLuckey; e-mail: mcluckey@purdue.edu methods [2]. With the development of electrospray ionization (ESI), many mass spectrometry-based methodologies have been established to elucidate the higher order structure of biomolecules. Under some conditions, evidence for partially folded states has been noted (vide infra).

Many publications have focused on studying the conformations of proteins using mass spectrometry-based techniques $[3,4]$. It was noted that proteins, as well as other biopolymers, form multiply charged ions when subjected to ESI, and that the conformation of a protein in solution is one of the factors that determine the charge state distribution (CSD) generated in ESI-MS [5-7]. ESI mass spectra obtained from solutions in which molecules are denatured tend to show higher charge states (lower $\mathrm{m} / \mathrm{z}$ ions) than spectra obtained from solutions conducive to the preservation of conformations in their native forms [8]. Tightly folded proteins are expected to have smaller surface areas 
compared with less-structured protein molecules and, thus, for the same approximate charge density, can accommodate fewer charges on the protein surface in the final stages of the ESI process. It has been noted, for example, that proteins present in solutions of low $\mathrm{pH}$, in which significant denaturation is expected, give rise to higher average charge states in the positive polarity $[4,9]$ than those prepared under conditions in which native structures are stable. Similarly, proteins ionized from a high $\mathrm{pH}$ solution tend to result in a higher average negative charge state in the negative polarity $[10,11]$. However, the CSD differences tend not to be as drastic as that noted in the positive polarity $[12,13]$. Other conformation studies have utilized ion mobility to probe gas-phase conformations [14]. In ion mobility studies, an ion's average collisional cross-section with a buffer gas is determined by how rapidly the ion moves through the buffer gas under the influence of a weak electric field [15]. Ion beam scattering has also been used to measure collision cross-sections for unsolvated proteins and these studies, like the ion mobility work, have found that protein ion cross-sections tend to increase with charge [16]. Also, H/D isotope exchange [17, 18] as well as pulselabeling $[19,20]$ experiments have been used in conjunction with MS to study protein folding. These techniques provide conformational information from which folding funnels for biomolecules of interest can be developed. These funnels are a two-dimensional representation of both the native folded state as well as transient folded intermediates and misfolded or partially folded forms at local energy minima [21]. These intermediate states, sometimes referred to as kinetic intermediates, are also of interest because their structures may reveal important details of the protein-folding process [22]. The technique described in this paper, which involves the exposure of ESI generated droplets to acidic or basic vapors in the counter-current drying gas of the atmosphere/vacuum interface, may provide a means for generating transient partially folded states for subsequent study as a result of the relatively rapid time-scale over which changes occur in the ESI process.

Many studies have also focused on the manipulation of the protein charge states in one direction or another for reasons other than the study of protein higher order structure. Increasing the charge state distribution is beneficial for bringing the distribution to a mass-to-charge range accessible by most mass spectrometers. The generation of higher charge states may also be desirable for tandem mass spectrometry of proteins and protein complexes. The manipulation of solution conditions, such as solvent composition and $\mathrm{pH}$, as well as the addition of "super-charging" agents [23-28] are noteworthy examples of measures used to increase CSDs. However, increasing charge can also complicate spectral analysis of mixtures that give rise to multiple peaks compressed within a small $\mathrm{m} / \mathrm{z}$ range. Thus, in some cases, such as mixture analysis, it may be desirable to decrease the charge state distribution, to increase the distance between peaks of different compounds so that they are easier to distinguish [29]. There are also cases in which it is desirable to generate protein charge states lower than those generated by ESI for tandem mass spectrometry [30]. A variety of approaches have been used to reduce charge states in ESI-MS, including the manipulation of solution conditions [31], the use of gas-phase ion/molecule proton transfer reactions [32-36], and the use of gas-phase ion/ion reactions [37, 38]. In addition, extractive electrospray ionization (EESI) has employed basic solvents infused at rates of $0.1-2 \mu \mathrm{L} / \mathrm{min}$ resulting in ion/molecule reactions in open air in the region between the basic reagent spray and the electrospray of the protein or peptide analyte [39]. Zenobi et al. have also published work using electrosonic spray ionization (ESSI) [40] in which volatile gaseous vapors were introduced to reduce the observed charge state. However, they were unsuccessful when conducting similar experiments with ESI or nano-ESI [41]. The ESSI experiments were also used to calculate an apparent gas phase basicity of proteins $\left(\mathrm{GB}_{\mathrm{app}}\right)$ based on the ion/molecule reactions. This was based on work performed by Williams et al., where the $\mathrm{GB}_{\text {app }}$ was determined by studying the deprotonation reactions between protein ions and volatile bases that were introduced into an FT-ICR instrument [42].

We have previously described a vapor introduction technique for the atmosphere/vacuum interface region of an ESI source in which the average charge state ( $q_{\text {ave }}$ ) of ions derived from a protein, in an unbuffered aqueous solution near neutral $\mathrm{pH}$, can be increased via the introduction of acidic vapors in the positive polarity [43] and basic vapors in the negative polarity [44]. Briefly, a secondary nitrogen line was incorporated into the instrument with nitrogen flowing over a reagent test tube [45]. The nitrogen flow entrains the reagent vapors and admits them with the curtain gas, which is introduced into the interface between the curtain and the orifice plates. These vapors interact with the electrospray generated droplet, effectively changing the $\mathrm{pH}$ of the droplet, resulting in the unfolding of a protein. In this work, emphasis is placed on shifting the charge state distribution to lower charge states, thereby effecting protein folding "onthe-fly" (i.e., during the evolution of ESI droplets).

\section{Experimental}

\section{Materials}

Ammonium hydroxide, acetic acid, and hydrochloric acid were purchased from Mallinckrodt (Phillipsburg, NJ, USA). All proteins (bovine cytochrome $c$, ubiquitin from bovine red blood cells, human hemoglobin, yeast enolase, horse heart myoglobin, bovine carbonic anhydrase, alcohol dehydrogenase from Saccharomyces cerevisiae and bovine hemin) as well as piperidine were purchased from SigmaAldrich (St. Louis, MO, USA). All samples were used without further purification. Protein solutions for both positive and negative nano-electrospray were prepared in water. Acetic acid was used to prepare the low $\mathrm{pH}$ samples 
and piperidine was used to prepare the high $\mathrm{pH}$ samples. Final protein concentrations were approximately $20-50 \mu \mathrm{M}$.

\section{Apparatus and Procedures}

All experiments were performed using a prototype version of a QqTOF tandem mass spectrometer (Q-Star Pulsar XL; SCIEX, Toronto, ON, Canada) modified to allow for ion trap CID and ion/ion reactions [46]. No ion/ion reactions were used in this work. Ionization was accomplished via a nano-ESI emitter, forming either $[\mathrm{M}-\mathrm{nH}]^{\mathrm{n}-}$ anions or $[\mathrm{M}+$ $\mathrm{nH}]^{\mathrm{n}+}$ cations of the proteins. The technique described utilizes an apparatus designed to allow for the introduction of volatile vapors into the interface along with the curtain gas as previously described elsewhere [45]. In all cases, a nitrogen flow of $0.3 \mathrm{~L} / \mathrm{min}$ was directed across a test tube containing approximately $20 \mu \mathrm{L}$ of the volatile reagent. The head space vapors eventually mix with the $\mathrm{N}_{2}$ curtain gas flow and the combined flow enters the region between the curtain plate orifice and the nozzle of the ESI interface, which is where the molecule/droplet interaction takes place. Typically, a sample is ionized via nano-ESI and then the metering valves are opened to introduce the reagent vapors as desired. In some cases, the charge states were difficult to resolve due to the presence of adducts (e.g., attached acid or base molecules), but these were easily removed using dipolar DC collision-induced dissociation (DDC-CID), a broad-band collisional activation technique [47-49].

\section{Results and Discussion}

Many factors contribute to the observed charge state distribution of proteins ionized using ESI or nano-ESI, such as the number of ionizable groups on the molecule, solution conditions, and instrument conditions (e.g., the source and interface operating conditions) [50]. For the experiments described in this study, proteins were initially dissolved under denaturing conditions, using either acid or base in solution, and then the ESI droplets were exposed to vapors that would be expected to change the $\mathrm{pH}$ in the droplet in a direction amenable to the native structure of the protein. Conclusions regarding the folding state in this work are derived from the resulting protein CSD versus that for the protein not subjected to vapor exposure. All experiments were conducted using a nano-ESI emitter placed a few millimeters from the $250 \mu \mathrm{m}$ diameter sampling orifice of the atmosphere/vacuum interface. Under these conditions, charged droplets/ions pass through the counter-current drying gas and into the sampling orifice within $1 \mathrm{~ms}$ [51]. Hence, the comparison of results with and without exposure of the charged droplets to acidic or basic vapors reflects processes that occur within this time period.

Previous studies involving the exposure of nano-ESI droplets generated from near neutral $\mathrm{pH}$ solutions to acidic and basic vapors have been interpreted on the basis of changes in the $\mathrm{pH}$ of the evolving droplets. Significant changes in CSDs have been attributed to acid or baseinduced conformational changes of the protein structures initially present at near neutral $\mathrm{pH}$. The magnitude of the change in droplet $\mathrm{pH}$ that is associated with exposure to the various acidic and basic vapors is currently under investigation. We have compared spectra derived from the vapor exposure experiments to series of spectra collected as a function of solution $\mathrm{pH}$ to determine what might be termed an "apparent $\mathrm{pH}$." We find, however, that comparisons of CSDs obtained from the leak-in experiments with spectra collected using solutions of known $\mathrm{pH}$ can be inconclusive because it is often the case that no bulk solution $\mathrm{pH}$ conditions can be found that resemble the CSDs noted in the leak-in experiments. This is likely due to different conditions and time-scales of the experiments, with the leakin experiments being more influenced by the kinetics of folding/unfolding. The subject of $\mathrm{pH}$ changes in the ESI plume under normal conditions (i.e., no exposure to either acidic or basic vapors) has been examined by various means and with different conclusions. For example, the examination of mass spectra of compounds with known pH-dependent dissociation characteristics in solution suggested $\mathrm{pH}$ changes of 3-4 units in the evolving droplets [52], whereas fluorescence measurements of $\mathrm{pH}$ sensitive dyes suggested $\mathrm{pH}$ changes of 1 unit or less [53]. By comparing nano-ESI spectra before and after vapor exposure, the leak-in experiments reflect $\mathrm{pH}$ changes that occur relative to any $\mathrm{pH}$ changes that may take place inherently in the ESI process. The exposure of acidic droplets to basic vapors and the exposure of basic droplets to acidic vapors can lead to dramatic changes in the apparent droplet $\mathrm{pH}$, as reflected in the comparisons of nano-ESI spectra before and after vapor exposure. Figure 1, for example, illustrates typical comparisons. Figure 1a-c illustrate a comparison relevant to the exposure of acidic droplets to basic vapors and Figure $1 \mathrm{~d}-\mathrm{f}$ provide a comparison relevant to the exposure of basic droplets to acidic vapors. Figure 1a shows a positive ion nano-ESI mass spectrum of cytochrome $c$ from a $\mathrm{pH} 2.8$ aqueous solution (no vapor exposure), Figure $1 \mathrm{~b}$ shows the positive ion mass spectrum obtained from the $\mathrm{pH} 2.8$ solution after exposure to piperidine vapors, and Figure 1c shows the positive ion nano-ESI mass spectrum from a $\mathrm{pH}$ 11.2 aqueous solution. Mass spectra were acquired from aqueous solutions of cytochrome $c$ prepared over a wide range of $\mathrm{pH}$ values and the spectrum of Figure $1 \mathrm{c}$ was the most similar to that of Figure 1b. Note that the signal-tonoise ratio of Figure $1 \mathrm{~b}$ is superior to that of Figure 1c. We attribute this to the fact that the ESI droplets are at least initially in the right-way-round condition $[12,54-56]$ in the leak-in experiment, whereas they are in the wrong-wayround condition when the solution $\mathrm{pH}$ is 11.2. Figure $1 \mathrm{~d}$ shows the negative ion nano-ESI mass spectrum of ubiquitin dissolved in a $\mathrm{pH} 12.5$ aqueous solution, Figure 1e shows the spectrum acquired after the exposure of the $\mathrm{pH} 12.5$ electrospray to acetic acid vapors, and Figure $1 \mathrm{f}$ shows the negative nano-ESI mass spectrum of ubiquitin from a $\mathrm{pH} 2.1$ 
(a)

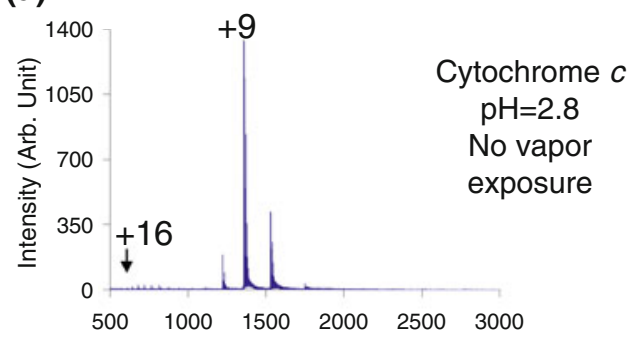

(b)

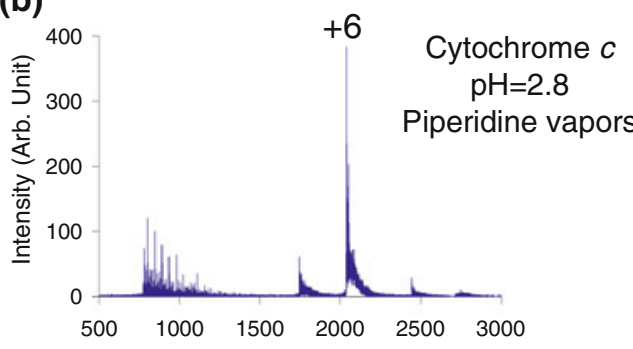

(c)

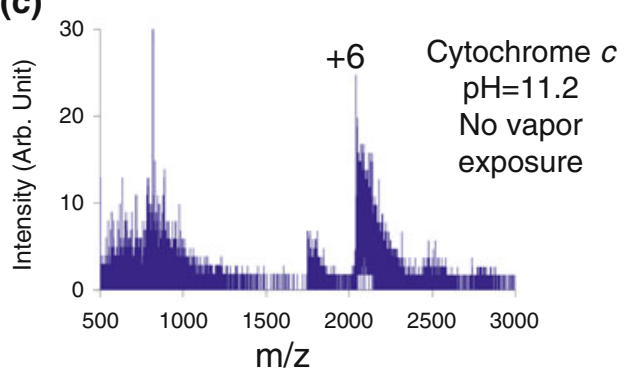

(d)

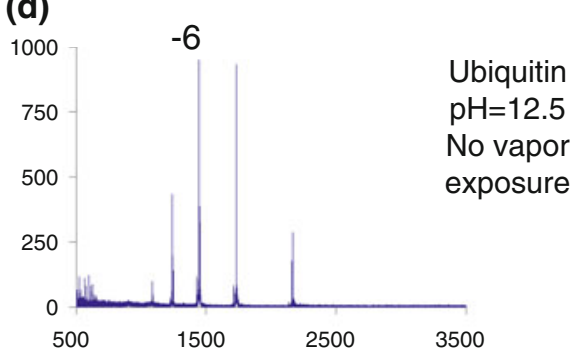

(e)

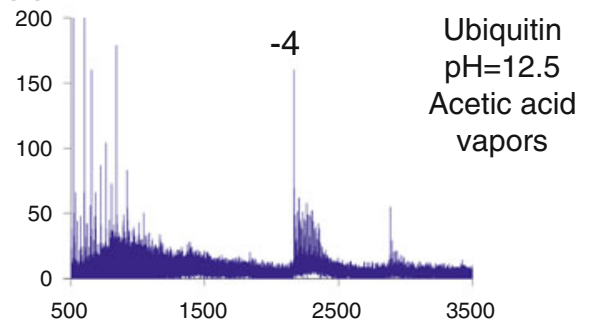

(f)

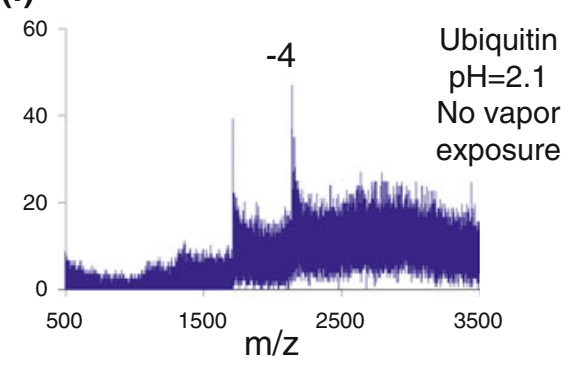

Figure 1. Positive nano-ESI spectra of cytochrome $c$ prepared at $\mathrm{pH}=2.8$ (a) and (b) and $\mathrm{pH}=11.2$ (c), with no vapor exposure (a) and (c), and piperidine vapor leak-in (b). Negative nano-ESI spectra of ubiquitin at $\mathrm{pH}=12.5$ (d) and (e) and $\mathrm{pH}=2.1$ (f), with no vapor exposure (d) and (f) and acetic acid vapor leak-in (e)

solution. The latter spectrum provided the closest match to Figure 1e of the dozen spectra obtained systematically as a function of $\mathrm{pH}$. While care must be taken in comparing nano-ESI spectra derived from the vapor exposure experiments with nano-ESI spectra collected at a solution $\mathrm{pH}$ adjusted to provide the best match, due to the difference in time-scales, it is apparent that changes of up to $10 \mathrm{pH}$ units can be effected when acidic droplets are exposed to basic vapors and vice versa. The following experiments, therefore, represent results from proteins exposed to a dramatic change in $\mathrm{pH}$ over the course of droplet evolution, which is expected to take place within a millisecond.

We note that previous studies involved the exposure of near neutral $\mathrm{pH}$ droplets to either acids or bases and that CSDs of relatively low charge prior to vapor exposure shifted (often dramatically) to higher charge CSDs. Increases in charge states do not occur via gas-phase ion/molecule reactions because such reactions require a highly exothermic charge separation. The spectral changes were therefore attributed to protein denaturation in the droplets. The reduction of charge states via ion/molecule proton transfer reactions, on the other hand, is well-known $[57,58]$. Hence, the reduction of charge states in the vapor leak-in experiments described here may also involve contributions from gas-phase processes. However, given the evidence for protein denaturation of initially native conformations upon vapor exposure in the previous studies, it is reasonable to surmise that at least some, and possibly most, of the spectral changes noted here are due to $\mathrm{pH}$ changes within the ESI droplets. In either case, changes in protein conformation are expected as charge states are reduced.

\section{Cytochrome c and Ubiquitin: Positive Polarity}

The charge state distributions of cytochrome $c[9,59]$ and ubiquitin [60-62] have been extensively studied [63]. Bovine cytochrome $c$ is a globular protein containing 104 amino acids (23 basic and 12 acidic amino acids) and one covalently attached heme group [64]. The unfolding of cytochrome $c$ has been studied in solution [65] and using the vapor introduction technique described here [43, 44]. Ubiquitin is a smaller protein with 12 basic and 11 acidic residues [66]. The structural transitions of these proteins have also been studied via ion mobility mass spectrometry 
$[67,68]$. For both proteins, the folding transitions that are observed depend on the degree of initial unfolding in solution. Proteins were prepared over a range of solution $\mathrm{pH}$ resulting in different charge state distributions being observed.

Cytochrome $c$ prepared at $\mathrm{pH}=2.8$ and ionized in the positive polarity resulted in a CSD from +7 to +20 $\left(\mathrm{q}_{\mathrm{ave}}=+9.4\right)$ (see Figure 1a). The leak-in of ammonia $(\mathrm{pKa}=9.25[69])$ resulted in a slight shift to a lower CSD from +6 to $+17\left(\mathrm{q}_{\mathrm{ave}}=+7.8\right)$ (data not shown). Exposure to a stronger base, piperidine $(\mathrm{pKa}=11.12$ [69]), resulted in a much greater shift leading to a CSD from +6 to +7 for cytochrome $c$ (see Figure 1b). Note the presence of a low abundance CSD at a relatively high charge in Figure 1a. When the solution $\mathrm{pH}$ was adjusted to 2.1 , the higher CSD from +10 to $+21\left(\mathrm{q}_{\mathrm{ave}}=+14.8\right)$, presumably arising from a more extensively denatured cytochrome $c$, dominated the spectrum (Figure 2a). This distribution shifted to a CSD from +6 to $+17 \quad\left(\mathrm{q}_{\mathrm{ave}}=+12.4\right)$ with the introduction of ammonia (Figure 2b). Exposure to piperidine vapor resulted in a much greater shift leading to a bimodal CSD with relatively abundant ions at +8 to +11 and another, more highly adducted, ion at +6 . The latter ion appears in the region of the CSD obtained when the less unfolded cytochrome $c$ sample (pH 2.8) was subjected to piperidine vapors (Figure 1b). It is not clear from these results if the initial CSDs of Figure 1a and Figure 2a represent two points on a continuum for the same overall conformation that represent different extents of elongation or if they represent two quite distinct conformational states. If the former situation were to be true, the leak-in experiments would be expected to reflect the degree of refolding from the initial overall conformation. If the latter situation were to prevail, the leak-in experiments would reflect refolding of the distinct conformational states. Further information, as might be provided via ion mobility measurements, might be able to distinguish between these cases. The main point here is that the leak-in experiment appears to be able to induce a degree of refolding for an initially unfolded protein. The introduction of vapors of bases with $\mathrm{p} K_{\mathrm{a}}$ values between those of ammonia and piperidine resulted in CSDs intermediate between those observed for ammonia and piperidine. All of the basic vapors previously used to increase the charge state distributions of proteins in the negative polarity were found to be capable of reducing protein CSDs in the positive polarity.

The ability to access multiple folding states of cytochrome $c$ is also suggested in experiments conducted when the protein was prepared in a $\mathrm{pH} 9.5$ aqueous solution and then subjected to acid vapor leak-in. Results from relevant experiments are summarized in Figure 3. Figure 3a, for example, shows the results from nano-ESI of a $\mathrm{pH} 2.8$ cytochrome $c$ solution, which results in a bimodal distribution with a CSD centered around +9 and another CSD centered around $+17\left(\mathrm{q}_{\mathrm{ave}}=+11.6\right)$. When ionizing a more acidic cytochrome $c$ solution $(\mathrm{pH}=2.3)$, the lower CSD largely disappears (Figure 3b) (see also Figure 1a and
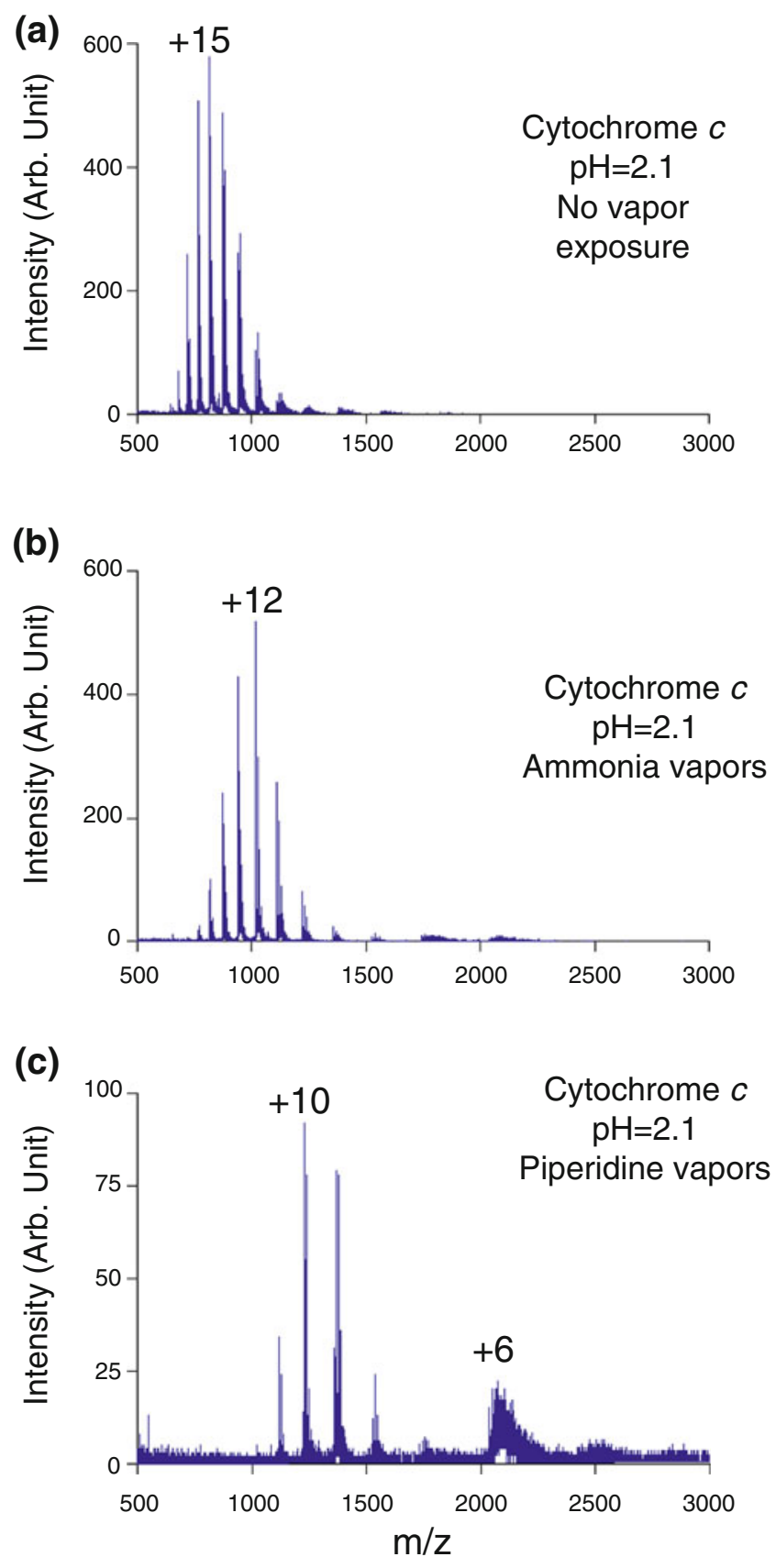

Figure 2. Positive nano-ESI spectra of (a)-(c) $\mathrm{pH}=2.1$ cytochrome $c$ with no vapor (a), ammonia vapor (b), and piperidine vapor (c) introduced to shift the charge state distributions to lower charge states

Figure 2a). These results suggest that the relative concentrations of the folding states that give rise to these distinct CSDs are readily altered via solution $\mathrm{pH}$. When cytochrome $c$ was prepared in a $\mathrm{pH} 9.5$ solution (CSD from +12 to +6 , $\mathrm{q}_{\mathrm{ave}}=9.0$ ) (Figure $3 \mathrm{c}$ ), and $\mathrm{HCl}$ vapors were introduced into the interface (Figure 3d), the apparently single CSD of Figure $3 \mathrm{c}$ transformed to two distinct CSDs in Figure 3d. A relatively high CSD, similar to that of Figure $3 b$, was generated along with a lower CSD centered at +7 . Cytochrome $c$ is known to fold into a molten globule state 
(a)

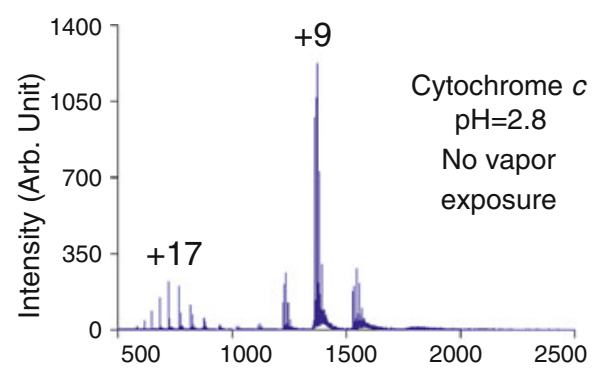

(b)

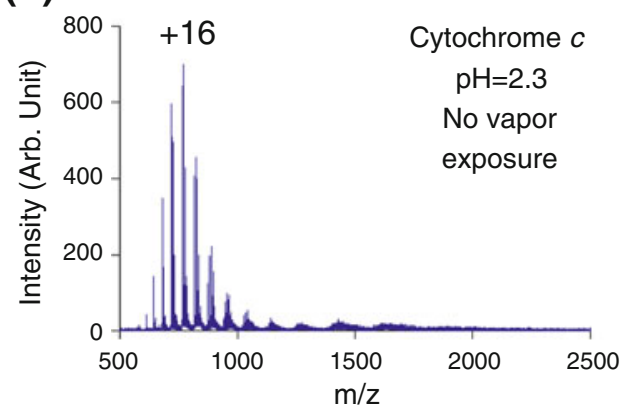

(c)

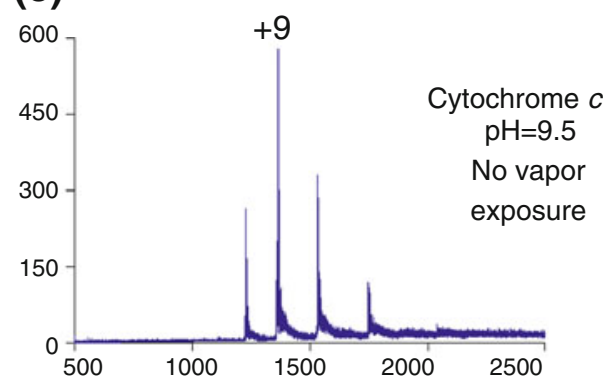

(d)

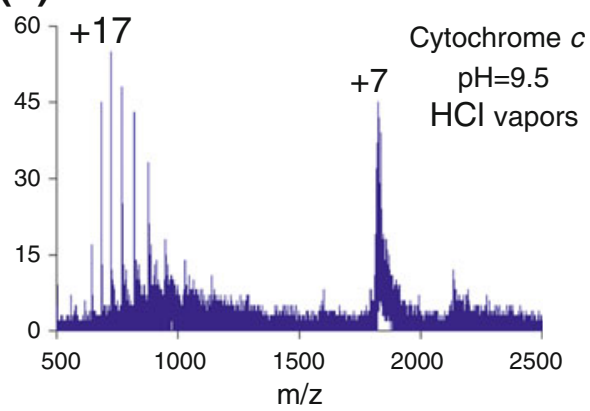

Figure 3. Positive nano-ESI spectra of cytochrome $c$ prepared at (a) $\mathrm{pH}=2.8$, (b) $\mathrm{pH}=2.3$, (c) and (d) $\mathrm{pH}=9.5$, with no vapor leak (a)-(c) and $\mathrm{HCl}$ vapor leak-in (d)

[70-75]. However, the bimodal distribution observed in Figure $3 \mathrm{~d}$ has not been observed for cytochrome $c$ prepared at any solution $\mathrm{pH}$. We noted the generation of the +7 charge state, however, in our previous work involving the exposure of ESI droplets generated from low $\mathrm{pH}$ cytochrome $c$ solutions to $\mathrm{HCl}$ vapors. A similar observation was observed when myoglobin was denatured in a $\mathrm{pH} 9.5$ solution with $\mathrm{HCl}$ vapors leaked-in (vide infra). These observations may reflect the formation of an intermediate folding state that is not observed directly from solution due to its relatively short lifetime and, therefore, distinguish the vapor leak-in experiment from experiments that vary the $\mathrm{pH}$ of the bulk solution.

Ubiquitin was also examined and is of interest because many folded states have been previously observed and studied via inter alia ion-molecule deprotonation [76] and time-resolved electrospray mass spectrometry experiments [77]. In our previous work with neutral $\mathrm{pH}$ solutions [43], the leak-in of weak acids resulted in a modest increase in $\mathrm{q}_{\text {ave }}(+7.8$ and +7.3 for acetic and formic acids, respectively) relative to the nano-ESI mass spectrum of a neutral $\mathrm{pH}$ solution $\left(\mathrm{q}_{\mathrm{ave}}=+6.8\right)$, whereas the leak-in of the strong acids TFA and $\mathrm{HCl}$ resulted in a distribution corresponding to the folded ubiquitin A-State or even a folding back to a more native state $(\mathrm{N}$-state) with an observed CSD from +4 to +8 $\left(\mathrm{q}_{\mathrm{ave}}=+5.9\right)$ [61]. In this work, for ubiquitin prepared at $\mathrm{pH}=$ 2.8 , the CSD shifted from +4 to $+13\left(\mathrm{q}_{\mathrm{ave}}=+6.9\right)$ prior to vapor leak-in (Figure $4 \mathrm{a})$ to a CSD from +4 to $+8\left(\mathrm{q}_{\mathrm{ave}}=+5.6\right)$ with the introduction of ammonia (Figure $4 \mathrm{~b}$ ) to one from +4 to $+5\left(\mathrm{q}_{\mathrm{ave}}=+5.0\right)$ with the introduction of piperidine vapors (Figure 4c). For the more unfolded ubiquitin prepared at $\mathrm{pH} 2.1$, the $\mathrm{CSD}$ shifted from +5 to +13 $\left(\mathrm{q}_{\mathrm{ave}}=+9.5\right)$ (Figure $\left.4 \mathrm{~d}\right)$ to a CSD from +4 to $+11\left(\mathrm{q}_{\mathrm{ave}}=+7.3\right)$ with ammonia vapor leak-in (Figure $4 \mathrm{e}$ ) and to a CSD from +4 to $+6\left(\mathrm{q}_{\mathrm{ave}}=+5.2\right)$ with the introduction of piperidine vapors (Figure 4f). Interestingly, the leak-in of both strong acid and strong base leads to a reduction in the charge state for positively charged ubiquitin ions. The dominant charge state in the case of acid leak-in is +6 whereas it is +5 in the case of base leak-in. Based on charge state alone, no conclusions can be drawn regarding the degree of similarity of the conformations of the low charge state ions observed with acid and base leak-in. The application of structural probes, such as ion mobility might shed light on this question.

The studies with cytochrome $c$ and ubiquitin in the positive ion mode illustrate several general observations noted with the base leak-in studies. In both cases, the leak-in of ammonia resulted in a smaller shift to lower charge than the leak-in of piperidine. Furthermore, the final CSDs are related to the initial CSDs. That is, initially more unfolded proteins with higher CSDs (lower $\mathrm{m} / \mathrm{z}$ ) show somewhat less charge state reduction than do less unfolded proteins with initially lower CSDs (higher $\mathrm{m} / z$ ). For instance, the initial CSD derived from the cytochrome $c \mathrm{pH} 2.8$ solution was converted essentially completely to the +6 charge state upon exposure to piperidine whereas the higher initial CSD derived from the $\mathrm{pH} 2.1$ solution was converted to a bimodal distribution comprised of a CSD similar to that of the initial $\mathrm{pH} 2.8$ solution as well as a +6 ion. Given the dynamic nature of the brief exposure of the evolving electrospray 
(a)

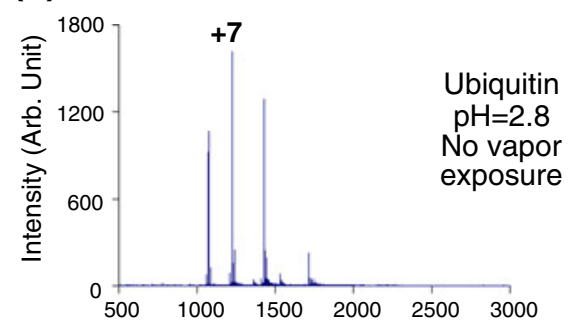

(b)
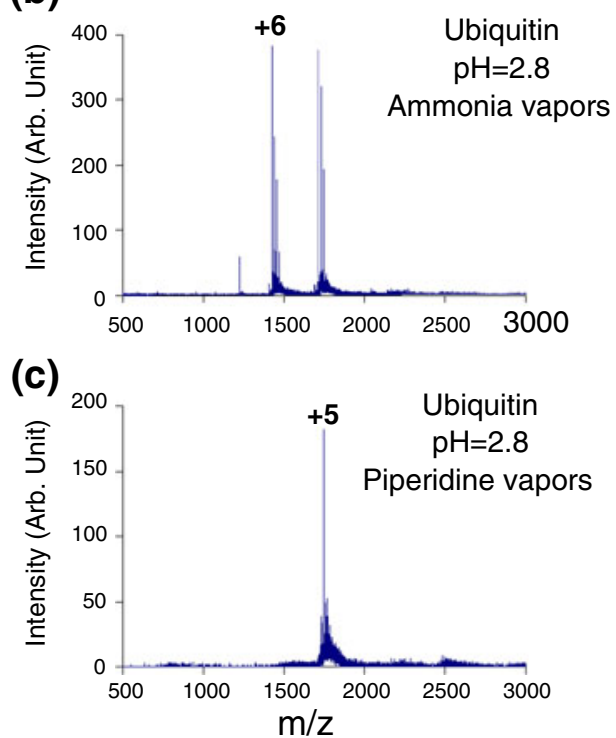

(d)

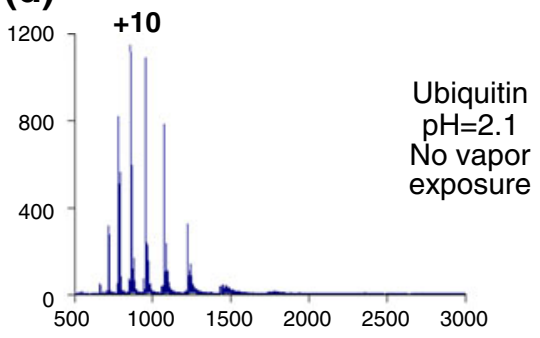

(e)

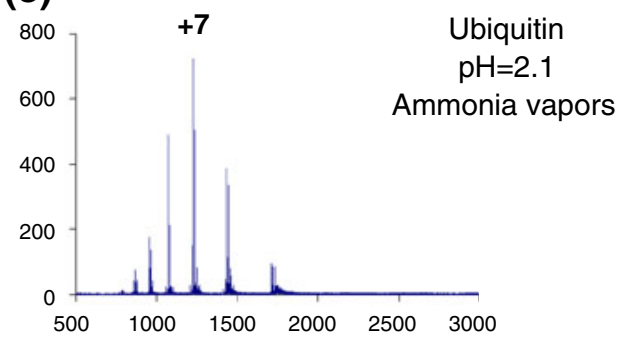

(f)

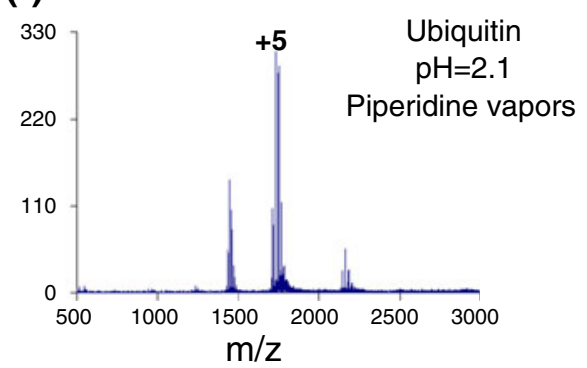

Figure 4. Positive nano-ESI spectrum of (a)-(c) $\mathrm{pH} 2.8$ ubiquitin and (d)-(f) $\mathrm{pH} 2.1$ ubiquitin, with no vapor leak (a) and (d), ammonia vapor (b) and (e), and piperidine vapor (c) and (f) leak-in to shift the charge state distributions to lower charge states

droplets to the basic vapors, these results suggest that the extent of refolding noted from the leak-in experiment can be affected by the initial $\mathrm{pH}$ of the solution, the strength of the base, and its concentration. Extensive adduct formation corresponding to attachment of multiple molecules of base, was also noted, particularly for piperidine, as the bases can form relatively stable proton-bound clusters with the protein charge sites.

\section{Cytochrome c and Ubiquitin: Negative Polarity}

Both proteins were also studied in the negative polarity using piperidine in solution prior to ionization to facilitate denaturation. The proteins in the piperidine containing solutions resulted in much higher negative CSDs than were observed in the absence of piperidine. When acidic vapors were leaked in, the CSDs shifted to lower negative charge states. The leak-in of a weak acid shifted the distribution slightly. When acids with lower $\mathrm{p} K_{\mathrm{a}} \mathrm{s}$ were introduced into the interface, the protein charge state distributions shifted further to lower negative charge states. All acidic vapors that were used to increase the charge state distribution in the positive polarity can be used to decrease the absolute charge state distribution in the negative polarity. In most cases, acetic acid was a strong enough acid to alter the CSD, shifting the CSD from -4 to $-11\left(\mathrm{q}_{\mathrm{ave}}=-7.3\right)$ for a $\mathrm{pH} 10$ cytochrome $c$ solution (Figure $5 \mathrm{a}$ ), to a CSD from -4 to -6 $\left(\mathrm{q}_{\mathrm{ave}}=-5.2\right)$ (Figure 5b). For a $\mathrm{pH} 12.5$ ubiquitin solution (Figure 1d), the CSD shifted from -4 to $-8\left(\mathrm{q}_{\mathrm{ave}}=-5.7\right)$ to a CSD from -3 to $-4\left(q_{\mathrm{ave}}=-3.7\right)$ with the leak-in of acetic acid (Figure 1e). As in the positive polarity, the final observed CSD is dependent upon the CSD prior to leak-in. However, as often noted in solution phase studies, it is much more difficult to observe very high negative charge states for proteins with more basic sites than acidic sites, as is the case for ubiquitin and cytochrome $c$. Distinct CSDs that would suggest the presence of separate folding states, like those noted in Figure $3 \mathrm{a}$ for cytochrome $c$ cations, were not observed in the negative polarity for either protein. The CSD changes in the negative polarity did not show abrupt changes from one CSD to another. Rather the initial CSD evolved gradually to a lower CSD upon acid leak-in. It is therefore less clear that the leak-in experiment is inducing major conformational changes based on measured CSDs. In all cases, ubiquitin evolved to a CSD from -3 to -4 and cytochrome $c$ evolved to a CSD from -4 to -6 upon acid leak-in. These charge states are similar to those observed when ionizing $\mathrm{pH} 2$ cytochrome $c$ or $\mathrm{pH} 2$ ubiquitin 
(a)

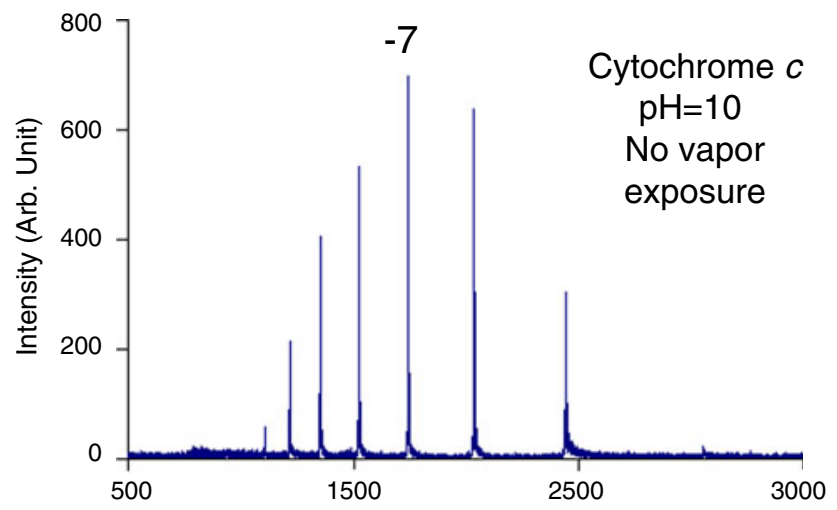

(b)

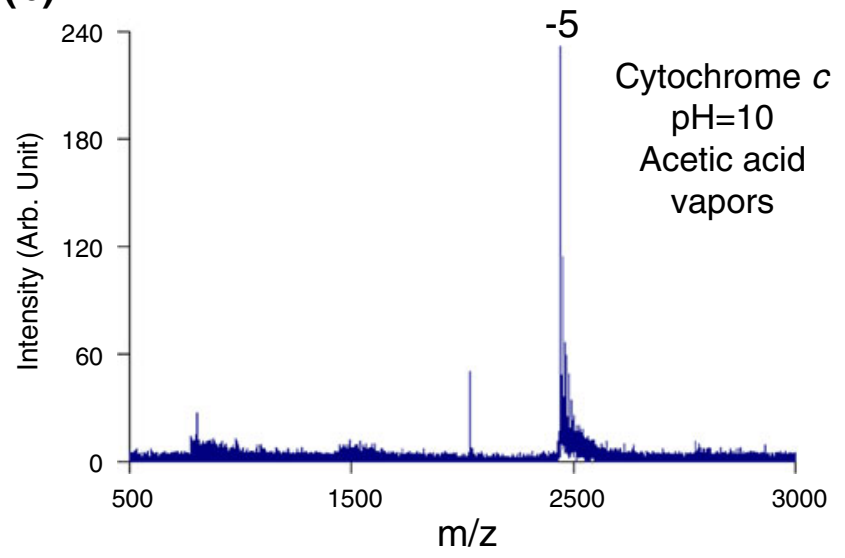

Figure 5. Negative nano-ESI spectra of a $\mathrm{pH}=10$ cytochrome $c$ solution with no vapor leak (a) and acetic acid vapor leak-in (b)

solutions in the negative polarity. However, the vapordroplet interaction results in much cleaner spectra, showing less metal ion incorporation and with a higher signal level, than ionizing in the wrong-way-round condition for both the negative and positive polarities.

\section{Proteins with Noncovalently-Bound Co-Factors}

Proteins that engage in specific noncovalent interactions were studied to determine the effects of vapor leak-in on the protein CSDs and whether disrupted noncovalent interactions can reform on the time-scale of the leak-in experiment. Myoglobin and carbonic anhydrase were both studied. Myoglobin, a widely studied protein in mass spectrometry, has a heme group that is noncovalently bound in a hydrophobic pocket of the protein in its holo-form [78]. ESI under gentle interface conditions and under non-denaturing solution conditions enables the noncovalent protein-heme interaction to be preserved [79-81]. Acid-induced denaturation in solution results in substantial unfolding of the polypeptide chain and disruption of the noncovalent hemeprotein interaction such that only the apo-form of the protein is observed. This denaturation proceeds through a short- lived intermediate that is substantially unfolded, but still retains the heme group [82]. The charge state distributions of myoglobin after denaturation as well as the reconstitution of the acid-denatured protein in the solution phase has been studied [83-86] and folding mechanisms have been proposed [87, 88]. Here, noncovalent interactions were studied by exposing droplets containing acid denatured proteins to basic vapors in the positive polarity and base denatured proteins to acidic vapors in the negative polarity. Myoglobin prepared in a $\mathrm{pH} 2.1$ solution and ionized in the positive polarity resulted in a CSD for unfolded apo-myoglobin centered around +21 (Figure 6a). When basic vapors were introduced into the counter-current drying gas, a bimodal distribution was observed with a distribution around the +13 charge state and another around +7 (Figure 6b). The peaks corresponded to apomyoglobin in both distributions, but the lower charge states contained more piperidine adducts. This bimodal distribution was not observed when ionizing myoglobin prepared at any solution $\mathrm{pH}$. When starting with a less unfolded myoglobin prepared at $\mathrm{pH}=4$, with $100 \mu \mathrm{M}$ hemin added, a CSD from +7 to +13 was observed with all of the peaks corresponding to holo-myoglobin peaks (Figure 6c). The introduction of piperidine vapor shifted the CSD to largely the +8 charge state with all of the peaks corresponding to holo-myoglobin (Figure 6d).

Myoglobin was also prepared at several basic $\mathrm{pH}$ solutions $(\mathrm{pH} 11$ and 12.5) and ionized in the negative polarity. When myoglobin was prepared at a $\mathrm{pH}$ of 11 , a CSD from -5 to -14 was observed, with $22 \%$ of the total myoglobin peaks corresponding to apo-myoglobin (Figure 7). When acetic acid was introduced into the interface, a shift to lower charge states was observed resulting in a CSD from -4 to -5 with all of the peaks corresponding to holo-myoglobin peaks (Figure 7b). The comparison of Figure $7 \mathrm{a}$ and $\mathrm{b}$ might suggest that the apo-myoglobin ions re-associate with available heme in the droplets upon acid exposure. However, the significant loss in total signal and poorer signal-to-noise ratio of Figure $7 \mathrm{~b}$ precludes a firm conclusion regarding this possibility. A higher, more negative distribution was observed when $\mathrm{pH} 12.5$ myoglobin was ionized in the negative polarity with a CSD from -7 to -22 being observed (Figure 7c), suggesting that the protein was more unfolded. When acidic vapors were introduced, two distributions were observed (Figure 7d). The higher CSD from -6 to -17 was predominantly centered around the -13 charge state with all of the peaks corresponding to apomyoglobin peaks. Another distribution was observed from -6 to -9 with a CSD for apo-myoglobin peaks and another for holo-myoglobin peaks. In this case, there is no compelling evidence that re-association of the heme group with apomyoglobin ions occurred. It is clear from this data that by changing the initial solution $\mathrm{pH}$, the ionization polarity, and the reagent vapors that are introduced, a variety of different folded and unfolded states can be studied. In the case when only $22 \%$ of the peaks did not have the heme group (Figure $7 \mathrm{a}$ ), the introduction of acetic acid resulted in only one CSD with 
(a)

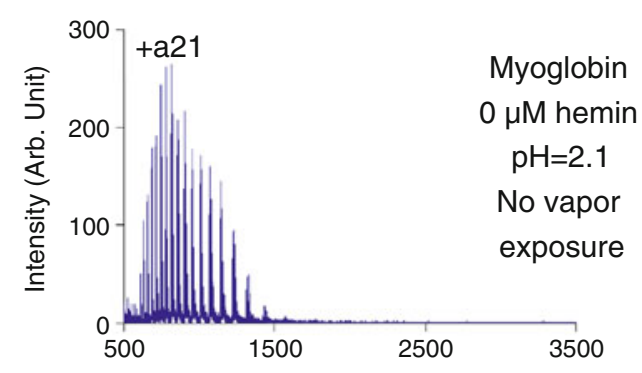

(b)

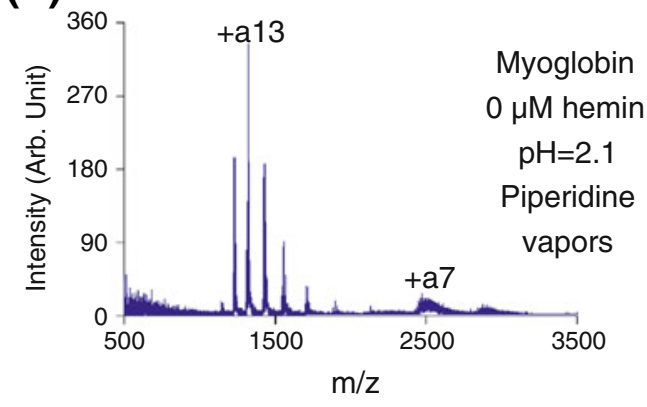

(c)

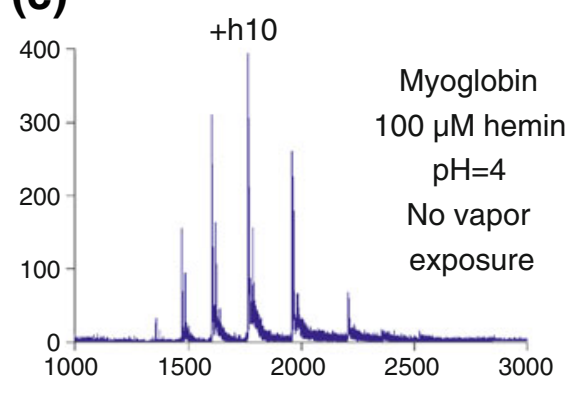

(d)

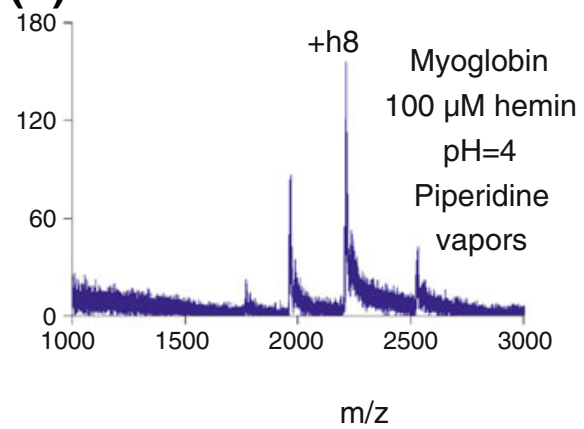

Figure 6. Positive nano-ESI spectrum of $\mathrm{pH} 2.1$ myoglobin (a)-(b) and pH 4 myoglobin with $100 \mu \mathrm{M}$ hemin (c)-(d), with no vapor exposure (a) and (c) and piperidine vapor leak-in (b) and (d). All of the peaks in (a) and (b) correspond to apomyoglobin peaks, while all of the peaks in (c) and (d) correspond to holomyoglobin peaks

all of the peaks corresponding to holo-myoglobin (Figure $7 b$ ). An increase in the relative contribution of ions that exhibit a noncovalent heme-myoglobin interaction was noted here only when the protein was not
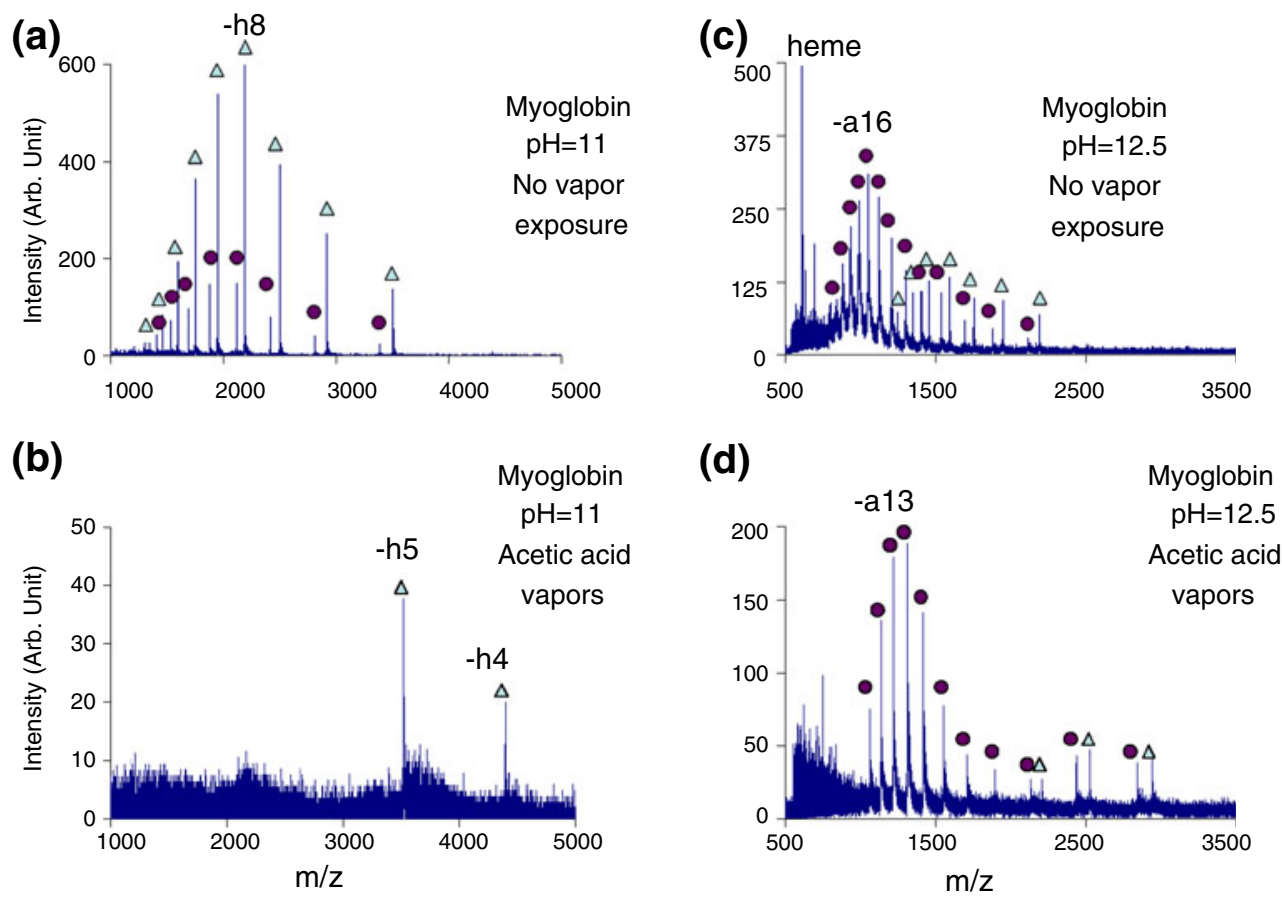

Figure 7. Negative nano-ESI spectrum of pH 11 myoglobin (a)-(b) and pH 12.5 myoglobin (c) and (d), with no vapor leak (a) and (c) and acetic acid vapor leak-in (b) and (d). (Peaks labeled with an open triangle $(\Delta)$ correspond to holomyoglobin peaks, while closed circles $(\mathbf{\bullet})$ represent apomyoglobin peaks) 
extensively denatured prior to reagent vapor introduction. Similar observations (data not shown) were also made with hemoglobin, another well studied protein with a noncovalently attached heme group [89, 90].

Heme aggregation in the presence of acid is common [91] and previous solution phase studies have found that the reconstitution of denatured holo-myoglobin led to the observation of myoglobin with more than one heme group $[92,93]$. When a $\mathrm{pH} 10$ myoglobin solution was subjected to nano-ESI in positive polarity, holo-myoglobin peaks with a CSD from +9 to +12 were observed (Figure 8a). When $\mathrm{HCl}$ vapors were introduced into the interface, higher charge state distributions $(+27$ to +14$)$ of both apo- and holo-myoglobin were observed, as well as a third distribution at the +8 to +9 charge states that corresponded to myoglobin with two heme groups (Figure 8b). DDC CID [47-49] was used to clean-up the spectra in order to better

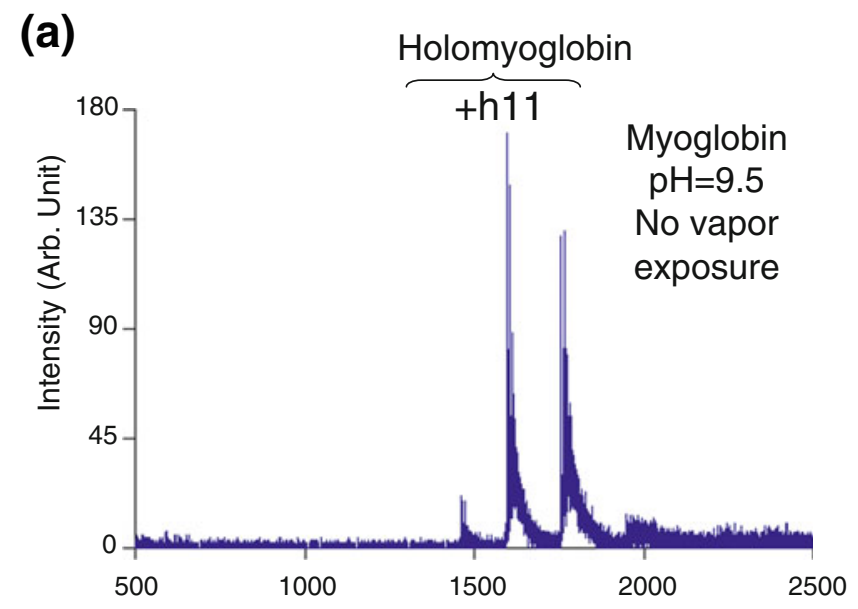

(b) Apo and Holo

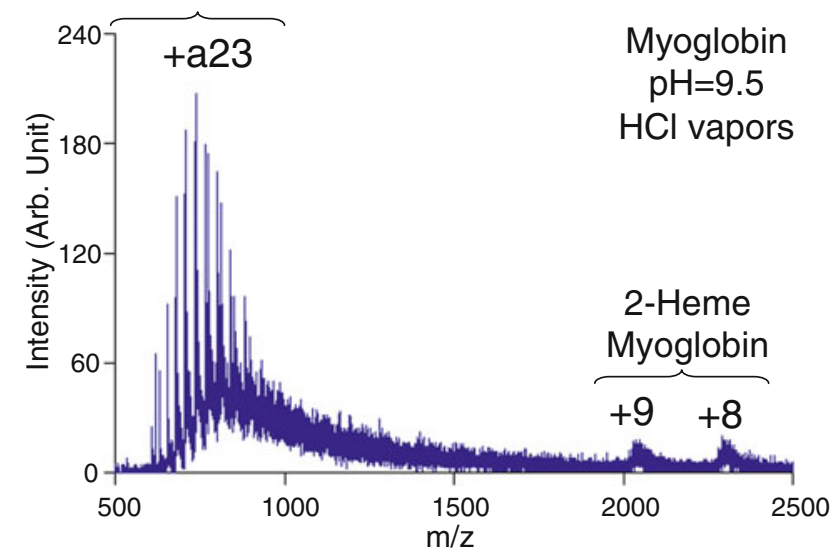

Figure 8. Positive nano-ESI spectrum of $\mathrm{pH} 9.5$ myoglobin with (a) no vapors and (b) $\mathrm{HCl}$ vapors introduced. Only holomyoglobin peaks are observed in (a), while a distribution for myoglobin with two heme groups attached is observed along with a holomyoglobin distribution (1-heme group present) and an apomyoglobin distribution (no heme groups present) in (b) determine the identity of the latter distribution. The observation of the three distinct myoglobin distributions (viz., apo-, holo-, and two heme versions) from a solution of holo-myoglobin prepared at basic $\mathrm{pH}$, ionized in the positive mode, and exposed to acid vapors might be rationalized in several ways. This may be a reflection of mixtures of conformational states in solution or it may reflect dynamic aspects associated with the leak-in experiment. The mass spectrum is an integration of results from exposure of the Taylor cone and the evolving electrospray droplets to the acidic vapor. Ions generated early in the process (i.e., from young droplets) likely experience a different environment than those generated late in the process. It is known that ions formed late in the ESI process tend to be of lower charge and show heavier degrees of adduction and sodium ion incorporation [94, 95]. Hence, the fact that the two-heme distribution was observed at low charge states and required heating via DDC CID to remove adducts suggests that these ions originated from somewhat older droplets. Similar reasoning can be applied to other results in this work (see Figure 3d, for example).

Separate experiments involving yeast enolase and alcohol dehydrogenase monomer ions present in acidic solutions exposed to piperidine vapors resulted in significant charge reduction but there was no evidence suggesting dimer formation. The kinetics for the association of two or more molecules is expected to show a concentration dependence, in contrast to the unimolecular folding/unfolding of a protein. Hence, further studies using higher protein concentrations than those typically employed in nano-ESI may be required to observe protein complex formation on the time-scale of the vapor exposure experiments described herein.

Carbonic anhydrase, like myoglobin, resulted in the appearance of a bimodal CSD when it was unfolded with piperidine in solution, ionized in the negative polarity, and exposed to acetic acid vapors. Carbonic anhydrase has a divalent zinc ion, which is an essential, noncovalently attached co-factor [96]. When this interaction is broken, much higher charge states for carbonic anhydrase can be observed [44]. When starting with carbonic anhydrase where the Zn-interaction is still present (Figure 9a) and acid is introduced, the CSD shifts to one with charge states from -7 to $-9\left(\mathrm{q}_{\mathrm{ave}}=-8.2\right)$ (Figure 9b). When ions derived from $\mathrm{pH} 12.5$ carbonic anhydrase (Figure 9c) are exposed to acid vapors, the distribution of high charge states (due to the broken noncovalent interaction) is shifted to a lowered CSD resulting in a distribution from -11 to -19 while the lower charge states (for which the noncovalent interaction is preserved) are shifted to a different CSD from -7 to -8 (Figure 9d). The lower CSDs in Figure $9 \mathrm{~b}$ and $d$ look similar suggesting that the distribution in which the noncovalent interaction is preserved shifts to a common set of charge states. The higher CSD (lower $\mathrm{m} / \mathrm{z}$ ) 

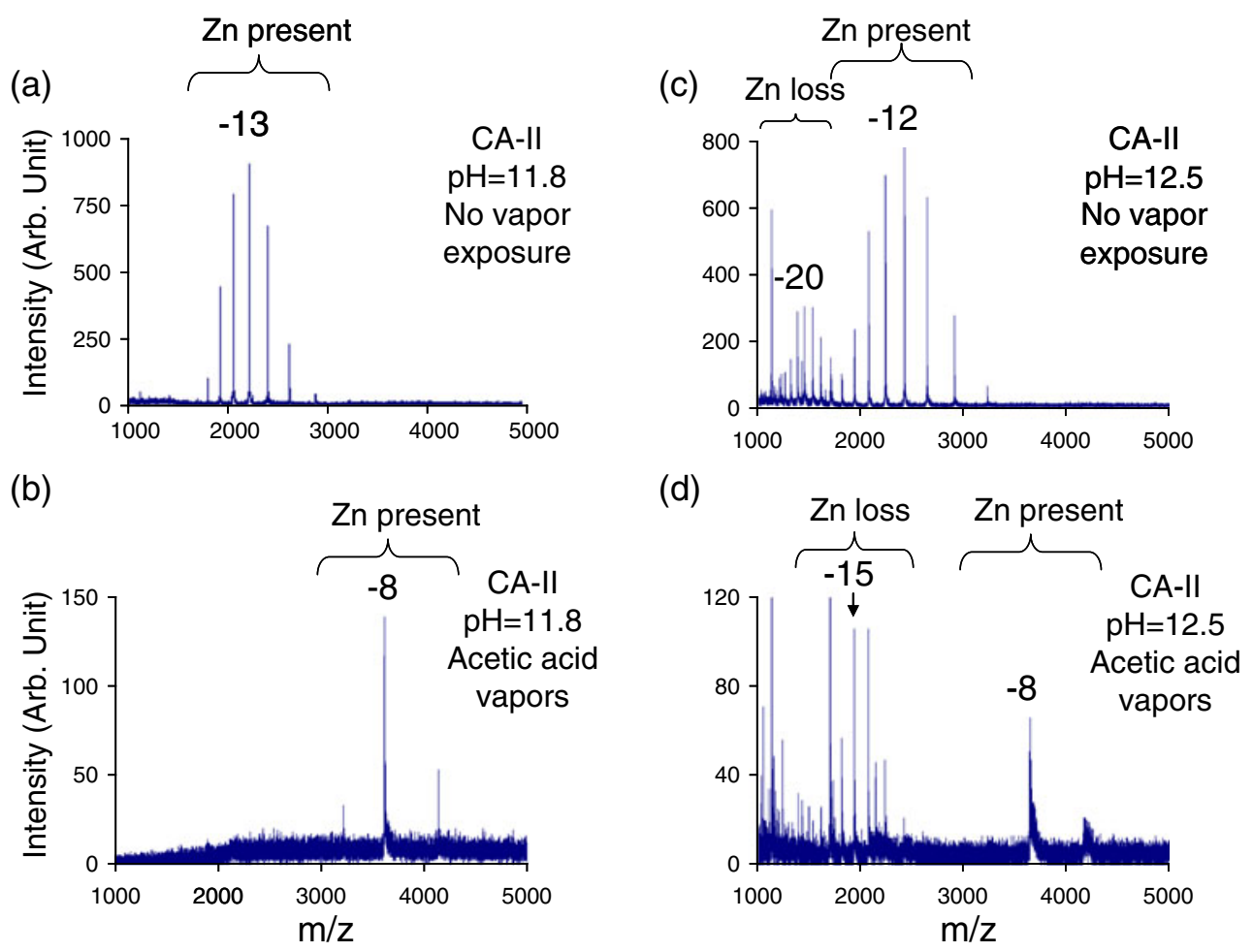

Figure 9. Negative nano-ESI spectrum of $\mathrm{pH} 11.8$ carbonic anhydrase (a)-(b) and $\mathrm{pH} 12.5$ carbonic anhydrase (c)-(d), with no vapor exposure (a) and (c) and acetic acid vapor leak-in (b) and (d)

observed in Figure 9d is obtained only when a CSD devoid of $\mathrm{Zn}$ noted in Figure 9c is initially present.

\section{Conclusions}

Proteins denatured by either acidic or basic conditions in aqueous solution, as reflected by the generation of distributions of relatively highly charged ions, can be subjected to a rapid change in $\mathrm{pH}$ by exposure to acidic or basic vapors admitted into the counter-current drying gas of an ESI atmosphere/vacuum interface. The resulting changes in CSDs to lower charge states and, sometimes, to bimodal CSDs are consistent with a degree of protein re-naturation in the evolving ESI droplets. The most dramatic $\mathrm{pH}$ changes occur when droplets generated from acidic solutions are exposed to basic vapors and when droplets generated from basic solutions are exposed to acidic vapors. The magnitude of the changes in the spectra noted here was dependent upon the initial solution $\mathrm{pH}$ and the $\mathrm{pK}_{\mathrm{a}}$ of the relevant acid or base used as the reagent vapor.

Other factors can affect the observed charge state distributions, such as the inherent gas phase basicity/acidity of the proteins as well as the reagents. However, in this work, many proteins were studied with varying isoelectric points [i.e., cytochrome $c(\mathrm{pI}=10.4)$, ubiquitin $(\mathrm{pI}=5.2)$, myoglobin $(\mathrm{pI}=7.2)$, and carbonic anhydrase $(\mathrm{pI}=5.9)]$ and similar results were obtained for these proteins. Also, proton transfer in the gas phase after the proteins have left the droplet could play a role in the observed charge state distributions. However, the presence of distinct bimodal distributions (see Figure $2 \mathrm{c}$ and Figure $6 \mathrm{~b}$ ) rather than a gradual stepwise change from one charge state distribution to another, often seen with gas-phase proton transfer reactions [32-42], suggests that the observed changes in the protein charge state distributions cannot be fully rationalized on the basis of gas-phase reactions. However, contributions from gas-phase proton transfer, at least to some extent, cannot be ruled out.

The millisecond time-scale associated with droplet evaporation and transport to the inlet aperture of the instrument places an upper limit on the extent of folding and complex formation that can take place. This kinetic constraint makes possible the observation of relatively short-lived conformational states that may be difficult to access simply by altering bulk solution conditions prior to ESI. In this sense, the leakin experiment can be regarded as a tool for expanding the study of protein conformational changes using mass spectrometry. Conclusions in this work were drawn from observed CSDs and the long-standing observation that CSDs can reflect conformational states in solution. However, the coupling of the vapor leak-in experiment with other structural probes, such as ion mobility and gas-phase H/D exchange, are attractive possibilities for providing further insights into conformational changes that may accompany the rapid $\mathrm{pH}$ changes in the droplets and the study of transient folding states. 


\section{Acknowledgments}

The authors acknowledge support for this work by the National Science Foundation under CHE-1111389, the American Chemical Society Division of Analytical Chemistry, and Agilent Technologies.

\section{References}

1. Dobson, C.M.: Protein folding and misfolding. Nature 426, 884-890 (2003)

2. Callender, R.H., Dyer, R.B., Gilmanshin, R., Woodruff, W.H.: Fast events in protein folding the time evolution of primary processes. Annu. Rev. of Phys. Chem. 49, 173-202 (1998)

3. Winston, R.L., Fitzgerald, M.C.: Mass spectrometry as a readout of protein structure and function. Mass Spectrom. Rev. 16, 165-179 (1997)

4. Kaltashov, I.A., Eyles, S.J.: Studies of biomolecular conformations and conformational dynamics by mass spectrometry. Mass Spectrom. Rev. 21, 37-71 (2002)

5. Felitsyn, N., Peschke, M., Kebarle, P.: Origin and number of charges observed on multiply-protonated native proteins produced by ESI. Int. J. Mass Spectrom. 219, 39-62 (2002)

6. McLafferty, F.W., Castro, S., Breuker, K.: Multi-step evolution of protein conformation on electrospray into the gas phase. Eur. J. Mass Spectrom. 16, 437-442 (2010)

7. Grandori, R.: Origin of the conformation dependence of protein chargestate distributions in electrospray ionization mass spectrometry. J. Mass Spectrom. 38, 11-15 (2003)

8. Chowdhury, S.K., Katta, V., Chait, B.T.: Probing conformational changes in proteins by mass spectrometry. J. Am. Chem. Soc. 112, 9012-9013 (1990)

9. Konermann, L., Douglas, D.J.: Equilibrium unfolding of proteins monitored by electrospray ionization mass spectrometry distinguishing two-state from multi-state transitions. Rapid Commun. Mass Spectrom. 12, 435-442 (1998)

10. Loo, J.A., Ogorzalek Loo, R.R., Light, K.J., Edmonds, C.G., Smith, R. D.: Multiply charged negative ions by electrospray ionization of polypeptides and proteins. Anal Chem. 64, 81-88 (1992)

11. Le Blanc, J.C.Y., Guevremont, R., Siu, K.W.M.: Electrospray mass spectrometry of some proteins and the aqueous solution acid/base equilibrium model in the negative ion detection mode. Int. J. Mass Spectrom. Ion Processes 125, 145-153 (1993)

12. Kelly, M.A., Vestling, M.M., Fenselau, C.C., Smith, P.B.: Electrospray analysis of proteins a comparison of positive-ion and negative-ion mass spectra at high and low pH. Org. Mass Spectrom. 27, 1143-1147 (1992)

13. Konermann, L., Douglas, D.J.: Unfolding of proteins monitored by electrospray ionization mass spectrometry a comparison of positive and negative ion modes. J. Am. Soc. Mass Spectrom. 9, 1248-1254 (1998)

14. Bohrer, B.C., Merenbloom, S.I., Koeniger, S.L., Hilderbrand, A.E., Clemmer, D.E.: Biomolecule analysis by ion mobility spectrometry. Annu. Rev. Anal. Chem. 1, 10.1-10.35 (2008)

15. Jarrold, M.F.: Unfolding, refolding, and hydration of proteins in the gas phase. Acc. Chem. Res. 32, 360-367 (1999)

16. Collings, B.A., Douglas, D.J.: Conformation of gas-phase myoglobin ions. J. Am. Chem. Soc. 118, 4488-4489 (1996)

17. Wood, T.D., Chorush, R.A., Wampler, F.M., Little, D.P., O'Connor, P. B., McLafferty, F.W.: Gas-phase folding and unfolding of cytochrome $c$ cations. Proceedings of the National Academy of Sciences 92, 24512454 (1995)

18. McLafferty, F.W., Guan, Z., Haupts, U., Wood, T.D., Kelleher, N.L.: Gaseous conformational structures of cytochrome c. J. Am. Chem. Soc. 120, 4732-4740 (1998)

19. Konermann, L., Simmons, D.A.: Protein-folding kinetics and mechanisms studied by pulse-labeling and mass spectrometry. Mass Spectrom. Rev. 22, 1-26 (2003)

20. Konermann, L., Stocks, B.B., Pan, Y., Tong, X.: Mass spectrometry combined with oxidative labeling for exploring protein structure and folding. Mass Spectrom. Rev. 29, 651-667 (2010)

21. Leopold, P.E., Montal, M., Onuchic, J.N.: Protein folding funnels akinetic approach to the sequence-structure relationship. Proc. Natl. Acad. Sci. USA 18, 8721-8725 (1992)

22. Dill, K.A., Chan, H.S.: From levinthal to pathways to funnels. Nature Struct. Biol. 4, 10-19 (1997)
23. Iavarone, A.T., Jurchen, J.C., Williams, E.R.: Supercharged protein and peptide ions formed by electrospray ionization. Anal. Chem. 73, 1455$1460(2001)$

24. Iavarone, A.T., Williams, E.R.: Supercharging in electrospray ionization effects on signal and charge. Int. J. Mass Spectrom. 219, 63-72 (2002)

25. Iavarone, A.T., Williams, E.R.: Mechanism of charging and supercharging molecules in electrospray ionization. J. Am. Chem. Soc. 2003 (125), 2319-2327 (2003)

26. Lomeli, S.H., Yin, S., Ogorzalek Loo, R.R., Loo, J.A.: Increasing charge while preserving noncovalent protein complexes for ESI-MS. $J$. Am. Soc. Mass Spectrom. 20, 593-596 (2009)

27. Lomeli, S.H., Peng, I.X., Yin, S., Ogorzalek Loo, R.R., Loo, J.A.: New reagents for increasing ESI multiple charging of proteins and protein complexes. J. Am. Soc. Mass Spectrom. 21, 127-131 (2010)

28. Sterling, H.J., Daly, M.P., Feld, G.K., Thoren, K.L., Kintzer, A.F., Krantz, B.A., Williams, E.R.: Effects of supercharging reagents on noncovalent complex structure in electrospray ionization from aqueous solutions. J. Am. Soc. Mass Spectrom. 21, 1762-1774 (2010)

29. Stephenson, J.L., Stephenson Jr., J.L., McLuckey, S.A.: Ion/ion reactions for oligopeptide mixture analysis Application to mixtures comprised of 0.5-100 kDa components. J. Am. Soc. Mass Spectrom. 9, 585-596 (1998)

30. Chanthamontri, C., Liu, J., McLuckey, S.A.: Charge state dependent fragmentation of gaseous $\alpha$-synuclein cations via ion trap and beamtype collisional activation. Int. J. Mass Spectrom. 283, 9-16 (2009)

31. Muddiman, D.C., Cheng, X., Udseth, H.R., Smith, R.D.: Charge state reduction with improved signal intensity of oligonucleotides in electrospray ionization mass spectrometry. J. Am. Soc. Mass Spectrom. 7, 697-706 (1996)

32. McLuckey, S.A., Van Berkel, G.J., Glish, G.L.: Reactions of dimethylamine with multiply charged ions of cytochrome c. J. Am. Chem. Soc. 112, 5668-5670 (1990)

33. Ogorzalek Loo, R.R., Loo, J.A., Udseth, H.R., Fulton, J.L., Smith, R. D.: Protein structural effects in gas phase ion/molecule reactions with diethylamine. Rapid Commun. Mass Spectrom. 6, 159-165 (1992)

34. Ogorzalek Loo, R.R., Smith, R.D.: Investigation of the gas-phase structure of electrosprayed proteins using ion-molecule reactions. J. Am. Soc. Mass Spectrom. 5, 207-220 (1994)

35. Ogorzalek Loo, R.R., Winger, B.E., Smith, R.D.: Proton transfer reaction studies of multiply charged proteins in a high mass-to-charge ratio quadrupole mass spectrometer. J. Am. Soc. Mass Spectrom. 5, 1064-1071 (1994)

36. Hunter, A.P., Severs, J.C., Harris, F.M., Games, D.E.: Proton-transfer reactions of mass-selected multiply charged ions. Rapid Commun. Mass Spectrom. 8, 417-422 (1994)

37. Scalf, M., Westphall, M.S., Krause, J., Kaufman, S.L., Smith, L.M.: Controlling charge states of large ions. Science 283, 194-197 (1999)

38. Stephenson Jr., J.L., McLuckey, S.A.: Ion/ion reactions in the gas-phase Proton transfer reactions involving multiply-charged proteins. J. Am. Chem. Soc. 118, 7390-7397 (1996)

39. Chen, H., Touboul, D., Jecklin, M.C., Zheng, J., Luo, M., Zenobi, R.: Manipulation of charge states of biopolymer ions by atmospheric pressure ion/molecule reactions implemented in an extractive electrospray ionization source. Eur. J. Mass Spectrom. 13, 273-279 (2007)

40. Touboul, D., Jecklin, M.C., Zenobi, R.: Investigation of deprotonation reactions on globular and denatured proteins at atmospheric pressure by ESSI-MS. J. Am. Soc. Mass Spectrom. 19, 455-466 (2008)

41. Touboul, D., Jecklin, M.C., Zenobi, R.: Rapid and precise measurements of gas-phase basicity of peptides and proteins at atmospheric pressure by electrosonic spray ionization-mass spectrometry. J. Phys. Chem. B 111, 11629-11631 (2007)

42. Schnier, P.D., Gross, D.S., Williams, E.R.: Electrostatic forces and dielectric polarizability of multiply protonated gas-phase cytochrome $c$ ions probed by ion/molecule chemistry. J. Am. Chem. Soc. 117, 67476757 (1995)

43. Kharlamova, A., Prentice, B.M., Huang, T., McLuckey, S.A.: Electrospray droplet exposure to gaseous acids for the manipulation of protein charge state distributions. Anal. Chem. 82, 7422-7429 (2010)

44. Kharlamova, A., McLuckey, S.A.: Negative electrospray droplet exposure to gaseous bases for the manipulation of protein charge state distributions. Anal. Chem. 83, 431-439 (2011)

45. Kharlamova, A., Prentice, B.M., Huang, T., McLuckey, S.A.: Electrospray droplet exposure to gaseous acids for reduction of metal counterions in nucleic acid ions. Int. J. Mass. Spectrom. 300, 158-166 (2011) 
46. Xia, Y., Chrisman, P.A., Erickson, D.E., Liu, J., Liang, X., Londry, F. A., Yang, M.J., McLuckey, S.A.: Implementation of ion/ion reactions in a quadrupole/time-of-flight tandem mass spectrometer. Anal Chem. 78, 4146-4154 (2006)

47. Tolmachev, A.V., Vilkov, A.N., Bogdanov, B., Păsa-Tolić, L., Masselon, C.D., Smith, R.D.: Collisional activation of ions in $\mathrm{rf}$ ion traps and ion guides The effective ion temperature treatment. J. Am. Soc. Mass Spectrom. 15, 1616-1628 (2004)

48. Webb, I.K., Londry, F.A., McLuckey, S.A.: Implementation of dipolar DC CID in storage and transmission modes on a quadrupole/time-offlight tandem mass spectrometer. Rapid Commun. Mass Spectrom. 25, 2500-2510 (2011)

49. Prentice, B.M., Santini, R.E., McLuckey, S.A.: Adaptation of a 3-D quadrupole ion trap for dipolar DC collisional activation. J. Am. Soc. Mass Spectrom. 22, 1486-1492 (2011)

50. Li, Y., Cole, R.B.: Charge state distributions in electrospray and MALDI. In: Cole, R.B. (ed.) Electrospray and MALDI Mass Spectrometry Fundamentals, Instrumentation, Practicalities and Biological Applications, 2nd edn, pp. 491-534. John Wiley and Sons, New York (2010). Chap 14

51. Schneider, B.B., Baranov, V.I., Javaheri, H., Covey, T.R.: Particle discriminator interface for nanoflow ESI-MS. J. Am. Soc. Mass Spectrom. 14, 1236-1246 (2003)

52. Gatlin, C.L., Tureček, F.: Acidity determination in droplets formed by electrospraying methanol-water solutions. Anal. Chem. 66, 712-718 (1994)

53. Zhao, S., Edwards, A.G., Cook, K.D., Van Berkel, G.J.: Investigation of the electrospray plume by laser-induced fluorescence spectroscopy. Anal. Chem. 71, 769-776 (1999)

54. Zhou, S., Cook, K.D.: Protonation in electrospray mass spectrometry Wrong-way-round or right-way-round? J. Am. Soc. Mass Spectrom. 11, 961-966 (2000)

55. Mansoori, B.A., Volmer, D.A., Boyd, R.K.: 'Wrong-way-round' electrospray ionization of amino acids. Rapid Commun. Mass Spectrom. 11, 1120-1130 (1997)

56. Le Blanc, J.C.Y., Wang, J., Guevremont, R., Siu, K.W.M.: Electrospray mass spectra of protein cations formed in basic solutions. Org. Mass Spectrom. 29, 587-593 (1994)

57. McLuckey, S.A., Van Berkel, G.J., Glish, G.L.: Reactions of dimethylamine with multiply charged ions of cytochrome c. J. Am. Chem. Soc. 112, 5668-5670 (1990)

58. Williams, E.R.: Proton transfer reactivity of large multiply charged ions. J. Mass Spectrom. 31, 831-842 (1996)

59. Grandori, R., Matecko, I., Muller, N.: Uncoupled analysis of secondary and tertiary protein structure by circular dichroism and electrospray ionization mass spectrometry. J. Mass Spectrom. 37, 191-196 (2002)

60. Brutscher, B., Bruschweiler, R., Ernst, R.R.: Backbone dynamics and structural characterization of the partially folded A state of ubiquitin by $1 \mathrm{H}, 13 \mathrm{C}$, and $15 \mathrm{~N}$ nuclear magnetic resonance spectroscopy. Biochemistry 36, 13043-13053 (1997)

61. Hoerner, J.K., Xiao, H., Kaltashov, I.A.: Structural and dynamic characteristics of a partially folded state of ubiquitin revealed by hydrogen exchange mass spectrometry. Biochemistry 44, 11286-11294 (2005)

62. Mohimen, A., Dobo, A., Hoerner, J.K., Kaltashov, I.A.: A chemometric approach to detection and characterization of multiple protein conformers in solution using electrospray ionization mass spectrometry. Anal. Chem. 75, 4139-4147 (2003)

63. Breuker, K.: Protein structure and folding in the gas phase ubiquitin and cytochrome $c$. In: Lifshitz, C., Laskin, J. (eds.) Principles of Mass Spectrometry Applied to Biomolecules, 1st edn, pp. 177-212. John Wiley and Sons, New York (2006). Chap. 5

64. Bushnell, G.W., Louie, G.V., Brayer, G.D.: High-resolution threedimensional structure of horse heart cytochrome c. J. Mol. Biol. 214, 585-595 (1990)

65. Goto, Y., Hagihara, Y., Hamada, D., Hoshino, M., Nishii, I.: Acidinduced unfolding and refolding transitions of cytochrome $c$ a threestate mechanism in $\mathrm{H}_{2} \mathrm{O}$ and $\mathrm{D}_{2} \mathrm{O}$. Biochemistry 32, 11878-11885 (1993)

66. Vijay-Kumar, S., Bugg, C.E., Cook, W.J.: Structure of ubiquitin refined at $1.8 \AA$ resolution. J. Mol. Biol. 195, 531-544 (1987)

67. Myung, S., Badman, E.R., Lee, Y.J., Clemmer, D.E.: Structural transitions of electrospray ubiquitin ions stored in an ion trap over 10 ms to 30 s. J. Phys. Chem. A 106, 9976-9982 (2002)
68. Clemmer, D.E., Hudgins, R.R., Jarrold, M.F.: Naked protein conformations cytochrome $c$ in the gas phase. J. Am. Chem. Soc. 117, 1014110142 (1995)

69. Lide, D. E., Ed. CRC Handbook of Chemistry and Physics, 82nd ed.; CRC Press: Boca Raton, FL, (2001-2002)

70. Goto, Y., Calciano, L.J., Fink, A.L.: Acid-induced folding of proteins. Proc. Natl. Acad. Sci. U.S.A. 87, 573-577 (1990)

71. Bychkova, V.E., Dujsekina, A.E., Klenin, S.I., Tiktopulo, E.I., Uversky, V.N., Ptitsyn, O.B.: Molten globule-like state of cytochrome $c$ under conditions simulating those near the membrane surface. Biochemistry 35, 6058-6063 (1996)

72. Grandori, R.: Detecting equilibrium cytochrome c folding intermediated by electrospray ionization mass spectrometry two partially folded forms populate the molten-globule state. Protein Sci. 11, 453-458 (2002)

73. Konermann, L., Collings, B.A., Douglas, D.J.: Cytochrome $c$ folding kinetics studied by time-resolved electrospray ionization mass spectrometry. Biochemistry 36, 5554-5559 (1997)

74. Maier, C.S., Kim, O.-H., Deinzer, M.L.: Conformational properties of the A-State of cytochrome $c$ studied by hydrogen/deuterium exchange and electrospray mass spectrometry. Anal. Biochem. 252, 127-135 (1997)

75. Mirza, U.A., Chait, B.T.: Effects of anions on the positive ion electrospray ionization mass spectra of peptides and proteins. Anal. Chem. 66, 2898-2904 (1994)

76. Cassady, C.J., Wronka, J., Kruppa, G.H., Laukien, F.H.: Deprotonation reactions of multiply protonated ubiquitin ions. Rapid Commun. Mass Spectrom. 8, 394-400 (1994)

77. Konermann, L., Pan, J., Wilson, D.J.: Protein folding mechanisms studied by time-resolved electrospray mass spectrometry. BioTechniques 40, 135-141 (2006)

78. Evans, S.V., Brayer, G.D.: High-resolution study of the three-dimensional structure of horse heart metmyoglobin. J. Molec. Bio. 213, 885897 (1990)

79. Katta, V., Chait, B.T.: Observation of the heme-globin complex in native myoglobin by electrospray-ionization mass spectrometry. J. Am. Chem. Soc. 113, 8534-8535 (1991)

80. Li, Y.-T., Hsieh, Y.-L., Henion, J.D.: Studies on heme binding in myoglobin, hemoglobin, and cytochrome $c$ by ion spray mass spectrometry. J. Am. Soc. Mass Spectrom. 4, 631-637 (1993)

81. Loo, J.A.: Studying noncovalent protein complexes by electrospray ionization mass spectrometry. Mass Spectrom. Rev. 16, 1-23 (1997)

82. Konermann, L., Rosell, F.I., Mauk, A.G., Douglas, D.J.: Acid-induced denaturation of myoglobin studied by time-resolved electrospray ionization mass spectrometry. Biochemistry 36, 6448-6454 (1997)

83. Dobo, A., Kaltashov, I.A.: Detection of multiple protein conformational ensembles in solution via deconvolution of charge-state distributions in ESI MS. Anal. Chem. 73, 4763-4773 (2001)

84. Feng, R., Konishi, Y.: Stepwise refolding of acid-denatured myoglobin evidence from electrospray mass spectrometry. J. Am. Soc. Mass. Spectrom. 4, 638-645 (1993)

85. Sage, J.T., Morikis, D., Champion, P.M.: Spectroscopic studies of myoglobin at low $\mathrm{pH}$ heme structure and ligation. Biochemistry 30, 1227-1237 (1991)

86. Sogbein, O.O., Simmons, D.A., Konermann, L.: Effects of pH on the kinetic reaction mechanism of myoglobin unfolding studied by timeresolved electrospray ionization mass spectrometry. J. Am. Soc. Mass. Spectrom. 11, 312-319 (2000)

87. Gross, D.S., Zhao, Y., Williams, E.R.: Dissociation of heme-globin complexes by blackbody infrared radiative dissociation molecular specificity in the gas phase? J. Am. Soc. Mass Spectrom. 8, 519-524 (1997)

88. Hargrove, M.S., Krzywda, S., Wikinson, A.J., Dou, Y., Ikeda-Saito, M., Olson, J.S.: Stability of myoglobin a model for the folding of heme proteins. Biochemistry 33, 11767-11775 (1994)

89. Griffith, W.P., Kaltashov, I.A.: Highly asymmetric interactions between globin chains during hemoglobin assembly revealed by electrospray ionization mass spectrometry. Biochemistry 42, 1002410033 (2003)

90. Boys, B.L., Konermann, L.: Folding and assembly of hemoglobin monitored by electrospray mass spectrometry using an on-line dialysis system. J. Am. Soc. Mass Spectrom. 18, 8-16 (2007)

91. Adams, P.A.: The kinetics and mechanism of the recombinant reaction between apomyoglobin and haemin. Biochem. J. 159, 371376 (1976) 
92. Lee, V.W.S., Chen, Y.-L., Konermann, L.: Reconstitution of acid-denatured holomyoglobin studied by time-resolved electrospray ionization mass spectrometry. Anal Chem. 71, 4154-4159 (1999)

93. Simmons, D.A., Konermann, L.: Characterization of transient protein folding intermediated during myoglobin reconstitution by time-resolved electrospray mass spectrometry with on-line isotopic pulse labeling. Biochemistry 41, 1906-1914 (2002)
94. Juraschek, R., Dülcks, T., Karas, M.: Nanoelectrospray-More than just a minimized-flow electrospray ionization source. J. Am. Soc. Mass Spectrom. 10, 300-308 (1999)

95. Pan, P., Gunawardena, H.P., Xia, Y., McLuckey, S.A.: Nanoelectrospray ionization of protein mixtures solution $\mathrm{pH}$ and protein $\mathrm{pI}$. Anal. Chem. 76, 1165-1174 (2004)

96. Saito, R., Sato, T., Ikai, A., Tanaka, N.: Structure of bovine carbonic anhydrase II at $1.95 \AA$ resolution. Acta Crystallogr. D60, 792-795 (2004) 